\title{
Dynamic Testing of Free Field Response in Stratified Granular Deposits
}

\author{
L. Dihoru*, S. Bhattacharya ${ }^{* *}$, F. Moccia ${ }^{* * *}$, A.L. Simonelli***, C.A. Taylor ${ }^{*}$, G. Mylonakis ${ }^{*}$ \\ * University of Bristol, University Walk, Bristol, BS8 1TR, United Kingdom \\ **University of Surrey, Guildford, GU2 7XH, United Kingdom \\ ***University of Sannio, Piazza Roma 21, Benevento, 82100 Italy
}

\begin{abstract}
The dynamic free field response of two stratified deposits with different stiffness ratios between the top and the bottom layer was analysed by shaking table testing. The granular deposits were contained in a laminar shear box and subjected to a wide set of dynamic inputs with different frequency content. Two exploratory modal testing techniques were employed to measure the natural frequency of the individual layers and the results were employed in the calculation of the fundamental period of the overall stratified profile by an extended variant of the Madera procedure [1]. The dynamic response was investigated in relation to the frequency content of the dynamic excitation, the granular material properties and the stiffness characteristics of the enclosing container. The measured dynamic stiffness for the mono-layered and the bi-layered sand deposits compare well with previous empirical curves for sands increasing the confidence in the shaking table and shear stack testing as tools of dynamic investigation of granular media.
\end{abstract}

Keywords: layered soil, 1-g testing, laminar shear box, shaking table

\section{Introduction}

The shearing stress-strain behaviour of soils is key to understanding how sites and buildings respond to earthquakes. The effect of local soil conditions on the observed magnitude and patterns of seismic damage to buildings has been studied extensively in the last four decades [2-7]. The shearing behaviour of soils, notably the shear modulus and damping ratio were found to be the properties that govern dynamic soil-structure interaction at all strain levels. The measurement of these properties has been the central objective in numerous laboratory and field studies [8-13]. Among the various tools employed in the dynamic analysis of granular media, shaking table testing is an important one, due to its capability of reproducing a wide set of real and artificial seismic inputs with relevance for the free field response. A large number of shaking table studies [14-18] employ flexible container boxes ('shear stacks') designed to replicate the free field response of a soil in plane strain conditions. Their role is to shear the soil via vertically propagating shear waves produced by the accelerating shaking table. In a large scale shear stack a large volume of soil can be tested, therefore the results may be more representative of the prototype field conditions. The boundary effects in a large shear stack are smaller than in table-top shear devices and the volume of soil situated in the central part of the container reproduces better the free field conditions for a given wavelength. It is also known that the design of a shear stack can be tuned to operate over wide strain ranges with granular materials of different stiffness value [19]. This, in particular, makes the shear stack useful for studying the large-strain dynamic moduli under seismic excitation. Several laminar shear box designs have been reported for both uniaxial and biaxial loading [2026]. While there is a large body of literature on tests on homogeneous soils, experimental data on stratified deposits is scarce. This paper presents an experimental programme of dynamic testing 
carried out on three deposits of dry granular material at Bristol University. An homogeneous deposit of sand and two bi-layered deposits of sand and rubber granules were tested in a uniaxial shear stack. The shear stack was assembled rigidly on the platform of a shaking table. Pulse tests and random white noise tests were carried out to measure the natural frequency of the individual layers. The fundamental periods of the stratified deposits were evaluated and compared to an analytical solution from the literature ([1]). The influences brought by the particulate material characteristics and the dynamic input parameters on the free field response were analysed. Aspects such as container-deposit coupling and deposit mode shapes were interpreted in relation to the deposit stiffness and the applied dynamic inputs.

\section{Experimental Programme}

\subsection{Shear Stack}

The shear stack employed in this study was a medium-sized uniaxial laminar container of length $1.2 \mathrm{~m}$, width $0.5 \mathrm{~m}$ and height $0.8 \mathrm{~m}$. The shear stack was built at Bristol University in 1993 [20] and has been since subjected to several design improvements directed in particular towards lowering its stiffness [27]. Previous investigations of the shear stack have shown that its fundamental frequency when empty is about $6 \mathrm{~Hz}$. The stack is active in one direction only, with its eight aluminium rings designed to move freely in the direction of shaking. The response in the other two directions is blocked by a steel rigid frame and a system of bearings. The stack end walls and base have a rough surface to allow complementary shear stresses to develop. Its side walls are lubricated to allow uniform plane strain conditions in the deposit. The shear stack is installed on the platform of a six-degrees-of-freedom earthquake simulator (the 'shaking table'). The shaking table consists of a $3 m \times 3 \mathrm{~m}$ cast aluminium platform weighing 3.8 tonnes and is capable of carrying a maximum payload of 15 tonnes. A wide set of dynamic inputs such as sinusoidal waves, sinusoidal sweep waves, real or artificial earthquakes can be reproduced, making the shaking table a versatile tool for dynamic testing. Horizontal accelerations of up to $3.7 \mathrm{~g}$ (with no payload) and up to $1.6 \mathrm{~g}$ (with 12 tonnes payload) can be achieved.

In this experimental project the shear stack was installed with its long side (shearing direction) on the $Y$ axis of the shaking table and the dynamic inputs were applied only on the $Y$ axis (Fig.1).

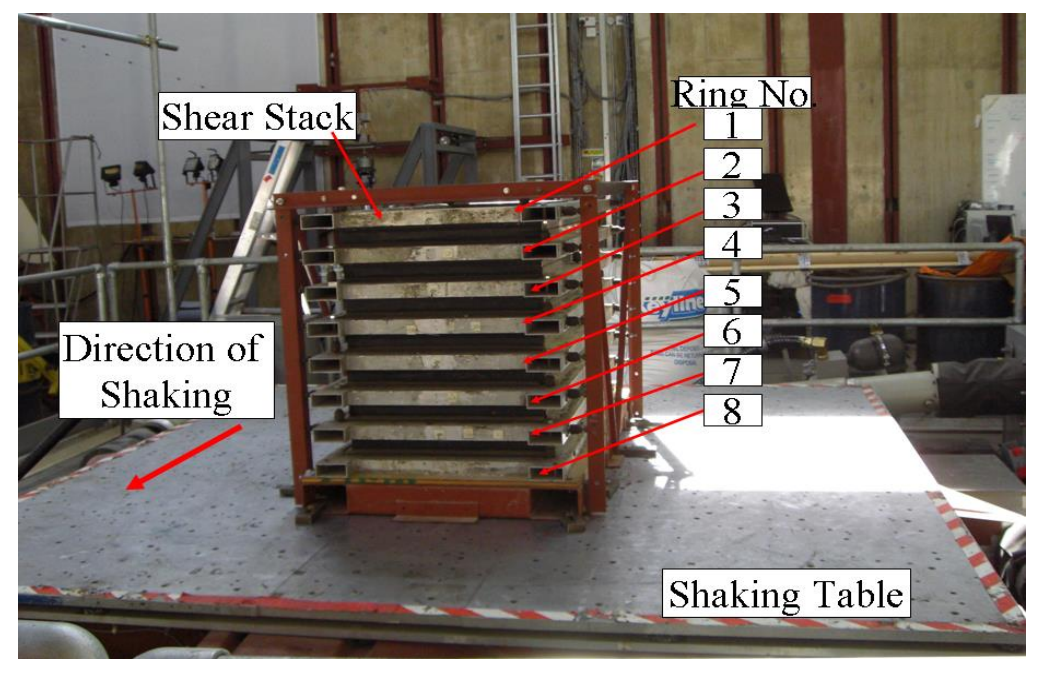

Fig. 1 The shear stack rigidly installed on the shaking table. 


\subsection{Materials and Experimental Set-Up}

The programme of testing employed three granular materials with different particle properties: Leighton Buzzard (LB) sand BS 881-131, Fraction B and Fraction E (Table 1) and rubber granules type Charles Lawrence CT0515B.

Table 1 Leighton-Buzzard sand BS 881-131 Fraction B and Fraction E particle size distribution

\begin{tabular}{|l|l|}
\hline BS 1881-131 Fraction B & BS 1881-131 Fraction E \\
\hline $1180 \mu \mathrm{m} 10 \%$ maximum retained & $150 \mu \mathrm{m} 15 \%$ maximum retained \\
\hline $600 \mu \mathrm{m} 10 \%$ maximum passing & $90 \mu \mathrm{m} \mathrm{15 \%} \mathrm{maximum} \mathrm{passing}$ \\
\hline $80 \%$ minimum between $1180 \mu \mathrm{m}$ and $600 \mu \mathrm{m}$ & $70 \%$ minimum between $150 \mu \mathrm{m}$ and $90 \mu \mathrm{m}$ \\
\hline
\end{tabular}

One monolayer configuration (E) and two layered configurations (BEE and ER) were built by pluviation. For the layered configurations, the median line of the enclosing container $(z=0.4 \mathrm{~m})$ marked the interface between the two layers of contrasting stiffness. The layout and the stiffness ratio between the top and the bottom layers for the selected configurations are shown in Fig. 2. A mixture of LB-Fraction B and LB-Fraction E particles was employed to model the stiff bottom layer in the BEE configuration. The mean diameter ratio between the two fractions of sands $\left(\mathrm{D}_{50}\right.$ Fraction $\mathrm{B}: \mathrm{D}_{50 \text {-Fraction } \mathrm{E}}=5.77$ ) was considered beneficial for an increase of packing when the two types of particles were mixed together. The fine particles were expected to fill in efficiently the voids in the large particle matrix. The mass composition (denoted by $X$ ) corresponding to the theoretical maximum packing density of the mixture was calculated according to a classic model of packing [28], resulting in $X_{\text {Fraction B }}: X_{\text {Fraction } E}=85: 15$.
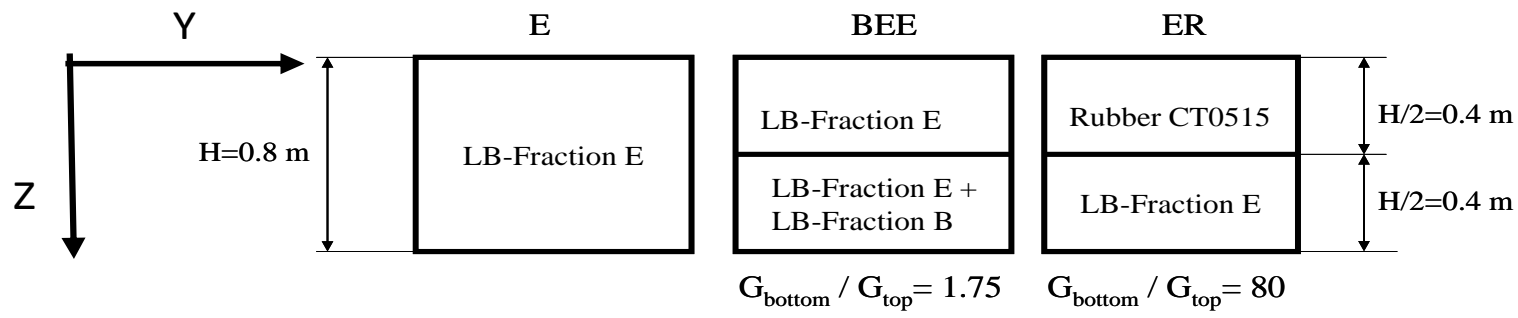

Fig.2 Deposit configurations employed in testing (E: monolayered, BEE and ER: two layered).

Further densification of the bottom layer after pluviation was achieved by tapping the deposit on a shaking table. After 10000 cycles of vertical sinusoidal vibrations of $10 \mathrm{~Hz}$, frequency and 0.35 $g$ amplitude, a $5 \%$ density gain was achieved (from $1840 \mathrm{~kg} / \mathrm{m}^{3}$ to $1942 \mathrm{~kg} / \mathrm{m}^{3}$ ) The upper prototype layer of lower stiffness was modelled with either Leighton Buzzard Fraction E (in the BEE configuration) or rubber granules CT0515 (in the ER configuration), respectively. The material properties, the parameters employed in pluviation and the experimentally obtained bulk densities are presented in Table 2. A uniform densification was achieved throughout the depth of the individual deposits.

Table 2 Material properties

\begin{tabular}{|l|c|c|c|}
\hline & $\begin{array}{c}\text { Rubber } \\
\text { Particles } \\
\text { CT0515 }\end{array}$ & $\begin{array}{c}\text { Sand } \\
\text { LB } \\
\text { Fraction E }\end{array}$ & $\begin{array}{c}\text { Sand } \\
\text { Mixture } \\
\text { Fraction B and Fraction E } \\
(85: 15)\end{array}$ \\
\hline Mean Diameter, D50 $(\mathrm{mm})$ & 1 & 0.142 & 0.82 \\
\hline Particle Morphology & irregular & angular & angular \\
\hline Particle Texture & rough & smooth & 2.65 \\
\hline Specific Gravity $\left(\mathrm{g} / \mathrm{cm}^{3}\right)$ & 1.15 & 2.65 & 0.31 \\
\hline Poisson's Ratio & 0.49 & 0.31 & $15 / 1000$ \\
\hline $\begin{array}{l}\text { Pluviation Parameters: } \\
\text { Nozzle Diameter }(\mathrm{mm}) / \mathrm{Height} \text { of Fall } \\
\text { (mm) }\end{array}$ & $15 / 1000$ & $40 / 1000$ & 1942 \\
\hline Pluviated Density $\left(\mathrm{kg} \mathrm{/} \mathrm{m}^{3}\right)$ & 479 & 31400 & \\
\hline
\end{tabular}


Four free-field accelerometers $\left(a_{1-5}\right)$ were embedded inside the deposit at similar coordinates in the horizontal plane $(x, y)=(0.270,0.455) \mathrm{m}$ and at vertical intervals of $\Delta z=0.2 \mathrm{~m}$ one from another. The response of the shear stack was measured by four accelerometers $\left(a_{6-9}\right)$ attached to the outside of the box rings (Fig. 3).
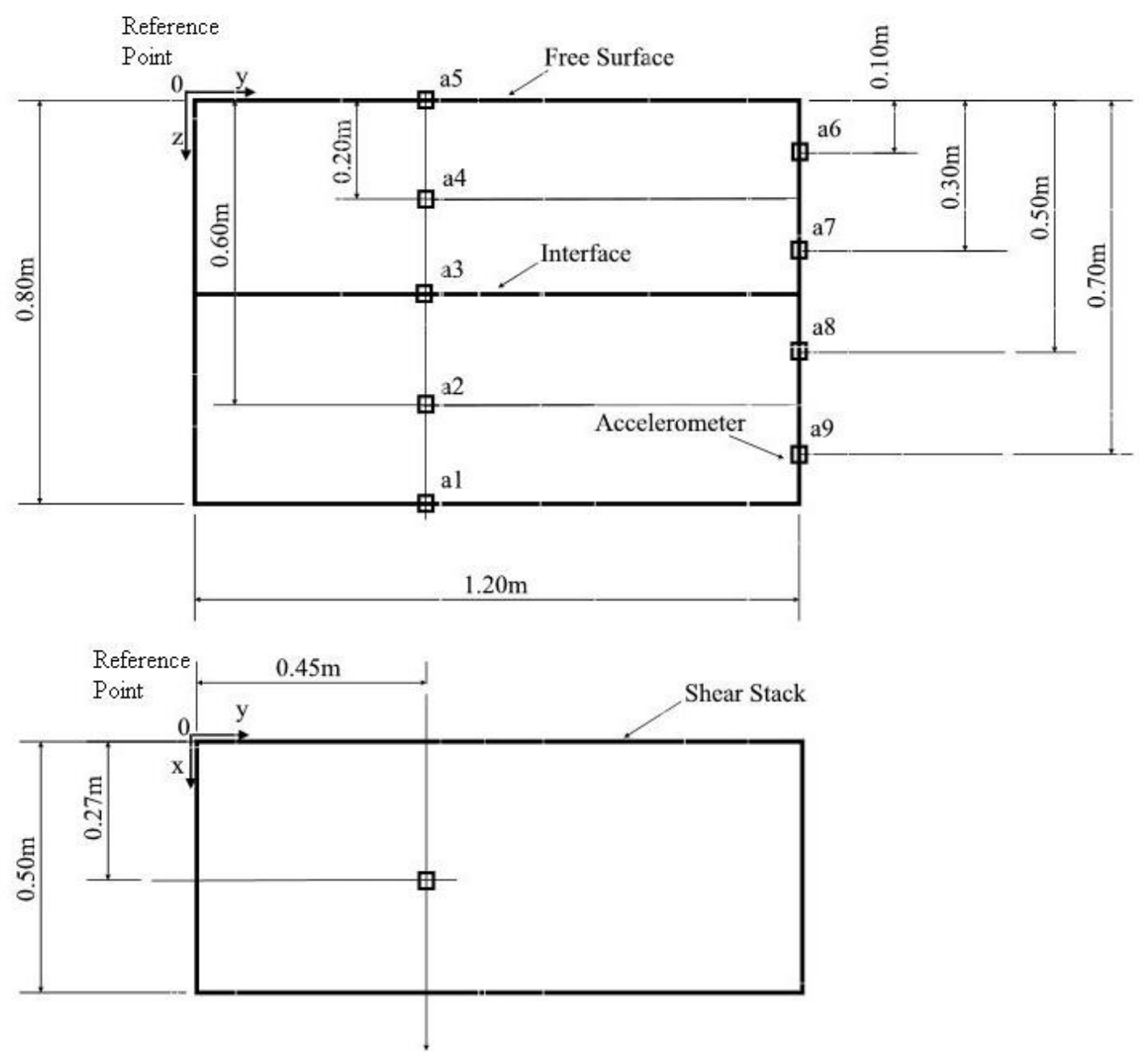

Fig. 3 Accelerometer layout in the shear stack (top: elevation, bottom: plan view, 'a': accelerometer position)

\subsection{Exploratory Modal Testing}

The low strain stiffness of the deposits was measured by modal testing involving sinusoidal pulses and random white noise. Pulse testing employed half-sinusoidal pulses of $10 \mathrm{~Hz}$ frequency, generated by the shaking table in the $Y$ direction. The measured travel time of the shear wave between accelerometers served for computing the shear wave velocity. The second modal testing technique employed a random white noise signal of $1-100 \mathrm{~Hz}$ bandwidth and $R M S=50 \mathrm{mV}$ ('Root Mean Squared' voltage) generated by the shaking table in the $Y$ direction. Frequency response functions (FRFs) were calculated by normalising the output of the receiving accelerometer $\left(a_{2-5}\right.$ in Fig.3) by the shaking table input in the frequency domain. The peaks of the FRF functions indicate frequencies of interest for both the granular deposits and the enclosing container. To avoid insufficient sampling of the data along the space axis ('spatial aliasing'), the vertical distance between adjacent accelerometers must be less than the half-wavelength of the shearing wave [29, 30]. For the experimental layout presented in Fig. 3, the distance between adjacent accelerometers 
is $0.2 \mathrm{~m}$. The first critical shear wavelength $\lambda_{\mathrm{c}}$ that would trigger spatial aliasing would be $0.4 \mathrm{~m}$. Thus, the critical aliasing frequencies were obtained from Eq.1:

$$
f_{c}=\left(G_{0} / \rho\right)^{1 / 2} / \lambda_{c}
$$

where: $G_{0}=$ small-strain shear modulus, $\rho=$ deposit density and $\lambda_{c}=$ critical shear wavelength.

By employing the shear wave velocities $\left(V_{s}\right)$ measured via white noise testing in Eq. 1, the critical aliasing frequencies for the materials employed were determined (Table 3). The calculated frequencies show that 'spatial aliasing' was not an issue for sand configurations. The critical aliasing frequency for the rubber layer was at the boundary of the frequency spectrum when large frequency scaling factors were used for the seismic input. For example, for an unscaled earthquake with a maximum energy content in the $2-4 \mathrm{~Hz}$ region (e.g. Friuli (1976) - Tolmezzo-A270), a 12time frequency scaling of the input motion will range close to the $24-48 \mathrm{~Hz}$ region.

Table 3 Calculation of 'spatial aliasing' frequencies for the individual deposits

\begin{tabular}{|l|c|c|c|c|c|}
\hline Material & $\rho\left(\mathrm{kg} / \mathrm{m}^{3}\right)$ & $G_{0}(\mathrm{MPa})$ & $V_{s}(\mathrm{~m} / \mathrm{s})$ & $\lambda_{c}(\mathrm{~m})$ & $f_{c}(\mathrm{~Hz})$ \\
\hline Rubber: CT0515 & 479 & 0.1 & 14 & 0.4 & 35 \\
\hline Sand: LB Fraction E & 1400 & 8 & 76 & 0.4 & 190 \\
\hline $\begin{array}{l}\text { Sand: mixture } \\
\text { LB Fraction B: LB Fraction E (85:15) }\end{array}$ & 1942 & 14 & 85 & 0.4 & 212 \\
\hline
\end{tabular}

To achieve a good representation of the measured signal, not only 'spatial aliasing' but also 'temporal aliasing' had to be prevented. 'Temporal aliasing' refers to under-sampling of data in the time domain. This was avoided by sampling at frequencies strictly greater than the double of the maximum frequency component within the measured signal. The sampling rate employed in this study was $1000 \mathrm{~Hz}$ in exploratory pulse and white noise tests and $200 \mathrm{~Hz}$ in seismic tests.

\subsection{Seismic Testing}

Unscaled and frequency scaled real acceleration records of three Italian earthquakes [Friuli (1976), Irpinia (1980) and Norcia (1998)] were used to drive the earthquake simulator. The acceleration time histories and the Fourier spectra of the chosen seismic records (Tolmezzo-A270, SturnoA000, and Norcia-R090) are shown in Fig. 4. The selected inputs have different energy distribution patterns and different Fourier amplitudes, therefore a good variety of soil responses could be obtained. Before being applied in the experiments, the amplitude of the signals was amplified in the time domain in order to reach a common peak ground acceleration value of $0.3 \mathrm{~g}$. The inputs were also frequency scaled at scaling factors (SF) of 2, 5 and 12 to shift the band of maximum seismic energy to higher frequency ranges. For example, the tests with an input scaling factor of 12 involved baseline frequencies in the $24-48 \mathrm{~Hz}$ range. In this manner, the influence of the frequency / energy content of the earthquake on the free field response could be explored. A summary of experimental programme detailing the soil configuration and the inputs for each test is presented in Table 4. 


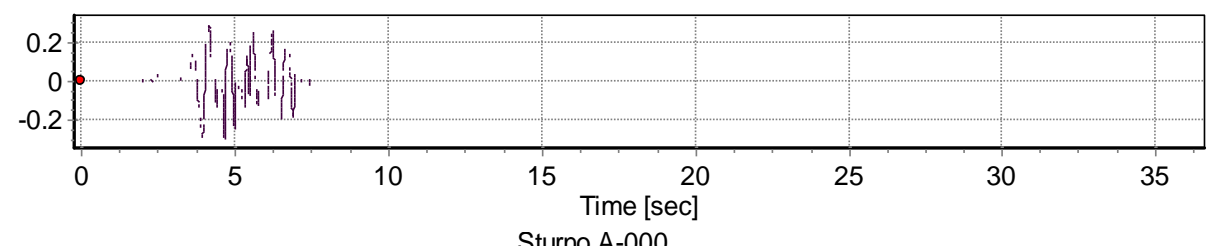

Sturno A-000
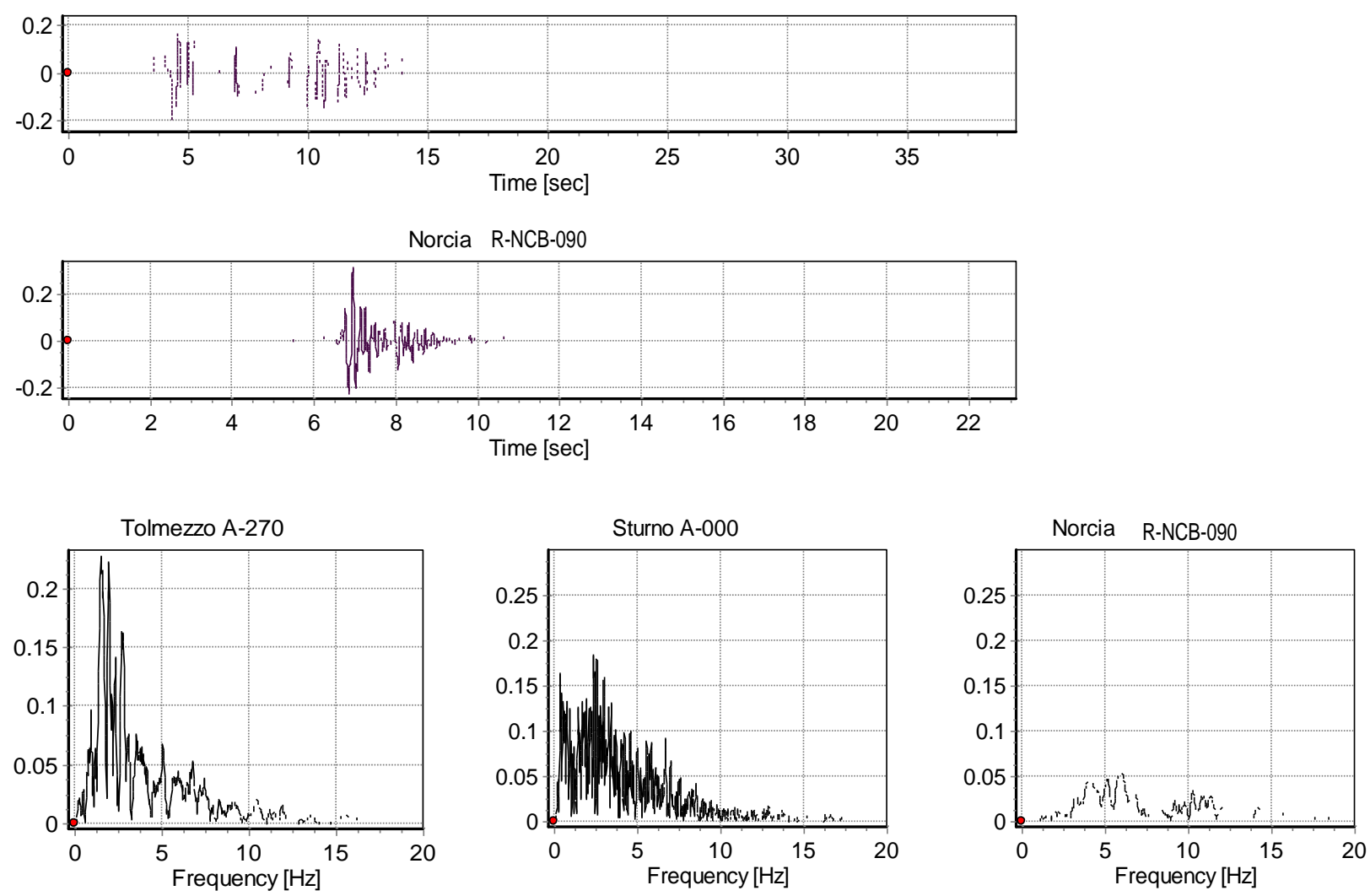

Fig.4 Selected seismic inputs: acceleration time histories (top) and Fourier spectra (bottom)

Table 4 Summary of experimental test programme

\begin{tabular}{|c|c|c|c|}
\hline Soil Configuration & Input Motion & Frequency Scaling Factor & Total Number of Tests \\
\hline E & Tolmezzo-A270 & $2,5,12$ & 9 \\
& Sturno-A000 & $2,5,12$ & \\
& Norcia-R090 & $2,5,12$ & 5 \\
\hline BEE & Sturno-A000 & $2,5,12$ & \\
& Tolmezzo-A270 & 2,12 & 9 \\
& & & \\
\hline ER & Tolmezzo-A270 & $2,5,12$ & \\
& Sturno-A000 & $2,5,12$ & \\
& Norcia-R090 & $2,5,12$ & \\
\hline
\end{tabular}

*Note: all acceleration time histories were amplified to reach a common peak ground acceleration value of $0.3 \mathrm{~g}$.

\section{Results and Discussion}

\subsection{Modal Testing}

Modal testing techniques that measure the shear wave velocity of the materials in 'as-pluviated' state in the shear stack can reveal a more realistic value of stiffness than the laboratory techniques 
employing small material samples confined in simplified boundary conditions (e.g. resonant column tests). Modal techniques employed 'in-situ' are believed to be less disturbing for the granular texture, therefore having more chance of capturing the small strain stiffness of the deposits.

In pulse testing, the shear wave velocity was inferred by measuring the vertical shear wave travel time between accelerometers located at certain ordinates in the deposits. Pulse testing is least disturbing, having thus the ability to capture the soil stiffness at very small strains. However, the measurements of shear wave velocity by pulse testing were found to be influenced by the signal amplitude and by the location of the receiving accelerometer (Fig.5). In addition, the evaluation of the arrival time of shear waves at the receiving end was a manual technique influenced by the subjectivity of the operator.

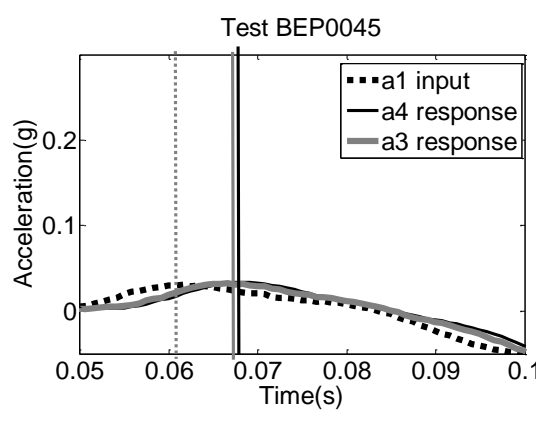

(a)

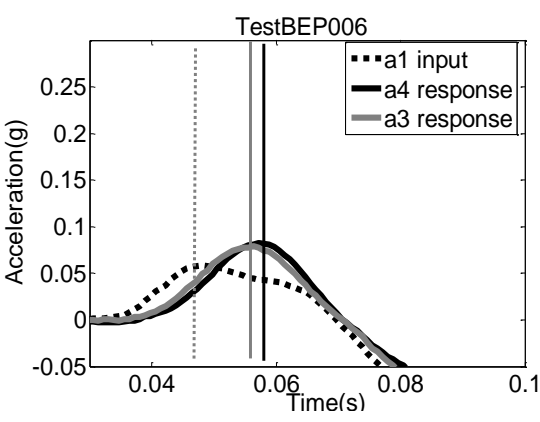

(b)

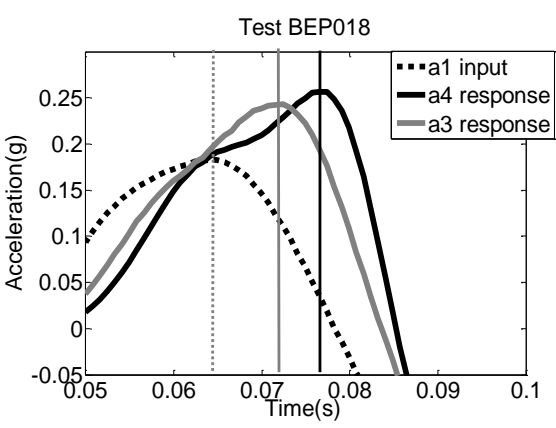

(c)

Fig. 5 Variation of response with input magnitude and location of receiver in pulse tests for sand mixture: LB-Fraction B:LB-Fraction E, input RMS: $0.045 \mathrm{~g}$ (a), $0.06 \mathrm{~g}$ (b), $0.18 \mathrm{~g}$ (c).

The shear wave velocity reported at the end of testing represented the average of the measurements taken in three different pulse tests carried out in similar conditions for each of the deposits selected. The granular deposits were assumed to behave elastically at low strain amplitudes (less than $10^{-3}$ $\%$ ). This allowed the theory of wave propagation through elastic media (the elastodynamic theory) to be applied. The shear modulus at low strain amplitude $\left(G_{0}\right)$ was obtained from the shear wave velocity $V_{s}$ and the soil mass density $\rho$ as in Eq.2:

$$
G_{0}=\rho V_{s}^{2}
$$

White noise testing involved the computation of frequency response functions (FRFs) for both the deposits and the shear stack. A frequency response function (FRF) is a transfer function, expressed in the frequency domain. Frequency response functions are complex functions, with real and imaginary components. They may also be represented in terms of magnitude and phase. In general, a frequency response function expresses the structural response (in this case the response of the soil layer) to an applied force (input signal) as a function of frequency. The response may be given in terms of displacement, velocity, or acceleration. In this project, the response is given as acceleration measured at various locations in the soil layer. White noise testing used a random noise signal of bandwidth $1-100 \mathrm{~Hz}$ and root mean square value (RMS) of the voltage amplitude $R M S=50 \mathrm{mV}$. The $R M S$ value of the voltage represents a statistical measure of the average magnitude of the voltage, otherwise known as a quadratic mean of the voltage. Frequency response functions (FRFs) were computed by normalising the output of the receiving accelerometer by the shaking table input in the frequency domain. The natural frequency of the test deposit was the frequency corresponding to the peak of the FRF functions. The stiffness of the deposit could be computed according to Eq. 3, assuming that the shear stack mode corresponds to a quarter of the wave length.

$$
G_{0}=16 \rho H^{2} f_{n}^{2}
$$


where $H$ is the height of the shear stack and $f_{n}$ is the natural frequency of the deposit.

By normalising the output of the accelerometers located inside the deposit by the shaking table input in the frequency domain, the frequency corresponding to the first mode of vibration could be obtained. As expected, the natural frequency increases from the loose to the dense deposits $\left(f_{n}\right.$ $=24 \mathrm{~Hz}$ for LB-Fraction E, $f_{n}=32 \mathrm{~Hz}$ for the sand mixture LB-Fraction B-LB-Fraction E) (Fig. 6). The natural frequency of the rubber CT0515 layer could not be determined in white noise tests, as this low density layer became decoupled from the shear stack motion. The shear stack "drives" the response, therefore the natural frequency of the rubber layer was believed to be lower than the natural frequency of the shear stack $\left(f_{n}\right.$-shear stack $\left.=6 \mathrm{~Hz}\right)$. Similarly to the pulse test results, the white noise measurements were found to depend on the input magnitude: higher input amplitude naturally leads to a lower frequency measurement (Fig.6).
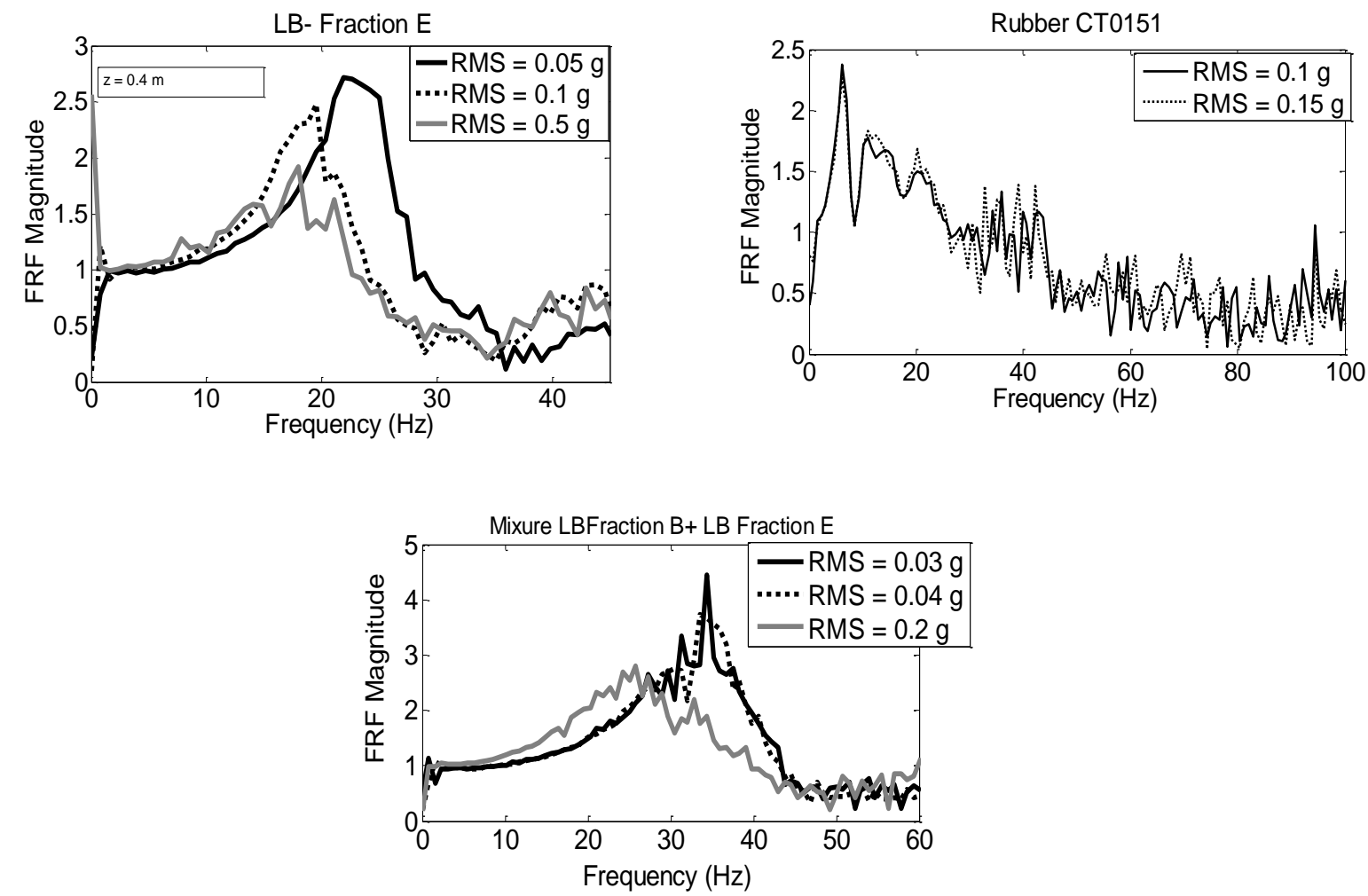

Fig.6 FRF (frequency response function) magnitude evolution with increasing input magnitude in white noise tests $(z=0.4 m$ in the deposit)

Both the pulse and the white noise test measurements were found to be influenced by the position of the accelerometer receiver and by the signal amplitude. In pulse testing the measured shear wave travel time was found to increase with the magnitude of input. Higher magnitude pulses release more energy in the granular texture, being more likely to disturb the initial fabric of the soil. More details on the exploratory tests can be found in $[31,32]$.

A summary of the average shear wave velocity $V_{s}$ data obtained in modal tests and of the computed small strain stiffness values $\left(G_{0}\right)$ is shown in Table 5 . The values reported for rubber are the ones obtained in the pulse tests. The values reported for sands represent average results obtained in pulse and white noise tests. As expected, $G_{0}$ increases with packing density from rubber CT0515 to the BEE sand mixture. 
Table 5 Average results from modal testing

\begin{tabular}{|l|c|c|c|}
\hline Modal Test Results & $\begin{array}{c}\text { Rubber } \\
\text { Particles } \\
\text { CT0515 }\end{array}$ & $\begin{array}{c}\text { Sand } \\
\text { LB } \\
\text { Fraction E }\end{array}$ & $\begin{array}{c}\text { Sand } \\
\text { Lixture }\end{array}$ \\
\hline Shear Wave Velocity, $\mathrm{V}_{\mathrm{s}}(\mathrm{m} / \mathrm{s})$ & 14 & 76 & 85 \\
\hline Max. Shear Stiffness, $\mathrm{G}_{0}(\mathrm{MPa})$ & 0.1 & 8 & 14 \\
\hline Fundamental Period, T $(\mathrm{s})$ & 0.221 & 0.043 & 0.038 \\
\hline Fundamental Frequency, $\mathrm{Hz}$ & 4.53 & 23.26 & 26.32 \\
\hline
\end{tabular}

\subsection{Evaluation of Fundamental Periods for the Deposits}

The measured fundamental period values for the decoupled granular layers were employed in the calculation of the fundamental period of the stratified deposits. The calculation employed an approximate analytical solution proposed by Hadjian [1] as an enhancement to the Madera procedure [33]. The Madera procedure consists of replacing the first two layers of an $N$-layer soil profile by an equivalent 'single' layer. This first equivalent 'single' layer and the third layer of the $N$-layer profile are then treated as the second two-layer system and, in turn, replaced by an equivalent single layer. The iterative application of this procedure yields the solution for the fundamental period of the total soil profile. The Madera procedure is chart based and presents inaccuracies associated with graphical interpolations between available discrete curves for $\mathrm{H}_{1} / \mathrm{H}_{2}$ (Fig.7, $H_{1}, H_{2}=$ widths of the individual soil layers, $T_{1}, T_{2}=$ decoupled fundamental periods of the individual soil layers).

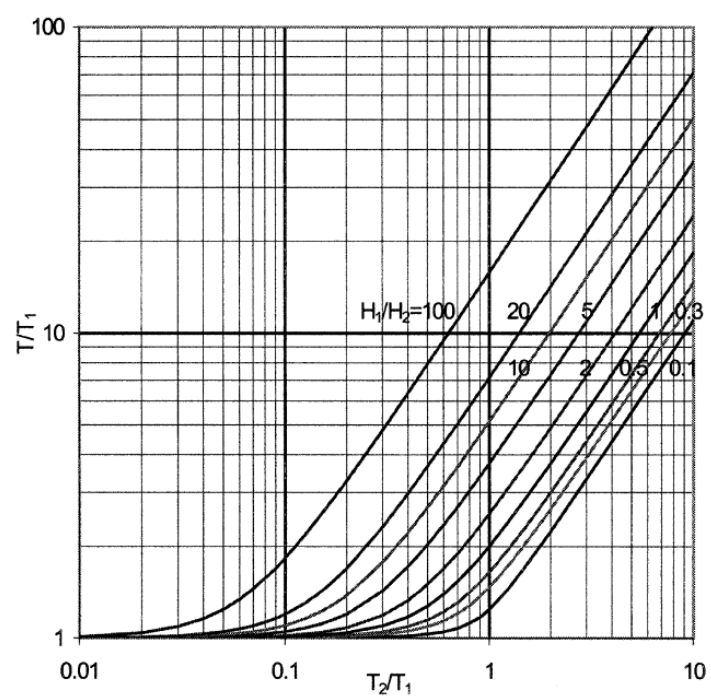

Fig.7 Graphical representation of the fundamental period solution for a two layer system [1].

The approximate analytical solution proposed by Hadjian [1] increases the calculation accuracy and can also cater for a variation of density across the soil profile (Eq. 4-6)

$$
\begin{aligned}
& \frac{T}{T_{1}}=\left[1+\beta\left(\frac{T_{2}}{T_{1}}\right)^{n}\left(1+\frac{H_{1} \rho_{1}}{H_{2} \rho_{2}}\right)^{n}\right]^{1 / n} \text { for } \frac{H_{1}}{H_{2}} \leq 1 \\
& \beta=1-0.2\left(\frac{H_{1} \rho_{1}}{H_{2} \rho_{2}}\right)^{2}
\end{aligned}
$$


$n=4-1.8\left(\frac{H_{1} \rho_{1}}{H_{2} \rho_{2}}\right)^{2}$

where $H_{1}\left(H_{2}\right)=$ height of top (bottom) layer, $\rho_{1}\left(\rho_{2}\right)=$ density of top (bottom) layer, $T_{1}\left(T_{2}\right)=$ decoupled fundamental period of top (bottom) layer, $T=$ fundamental period of the two-layer soil profile.

The fundamental period values calculated in this study for the ER and the BEE deposits are shown in Table 6.

Table 6 Calculation of equivalent fundamental period for a 2-layered deposit

\begin{tabular}{|l|c|c|c|c|c|}
\hline Deposit Configuration & $\mathrm{T}_{1}(\mathrm{~s})$ & $\mathrm{T}_{2}(\mathrm{~s})$ & $\mathrm{T} / \mathrm{T}_{1}$ & $\mathrm{~T}(\mathrm{~s})$ & $\mathrm{f}(\mathrm{Hz})$ \\
\hline ER & 0.221 & 0.043 & 1.064 & 0.235 & 4.25 \\
\hline BEE & 0.043 & 0.038 & 1.601 & 0.068 & 14.52 \\
\hline
\end{tabular}

It appears that the ER configuration $\left(f_{E R}=4.25 \mathrm{~Hz}\right)$ is less stiff than the shear stack $\left(f_{\text {shear stack }}=6\right.$ $\mathrm{Hz}$ ) and this may trigger the risk of soil decoupling from the enclosing container during dynamic testing. It is a fundamental requirement that the stack should be 'softer' than the deposit in order for the deposit to drive the response. It is only under these conditions that a realistic recreation of the soil shearing behaviour can be achieved.

\subsection{Seismic Free Field Response}

The time histories of the accelerometer signals inside the deposit and on the outside of the shear stack rings are instrumental in understanding basic aspects of shear wave propagation and motion coupling under seismic excitation. Figure 8 shows amplitude increase ('sand column amplification') and wave delay as the shear wave travels through the deposit vertically from the base $(\mathrm{z}=0.8 \mathrm{~m})$ to the top $(z=0 \mathrm{~m})$.

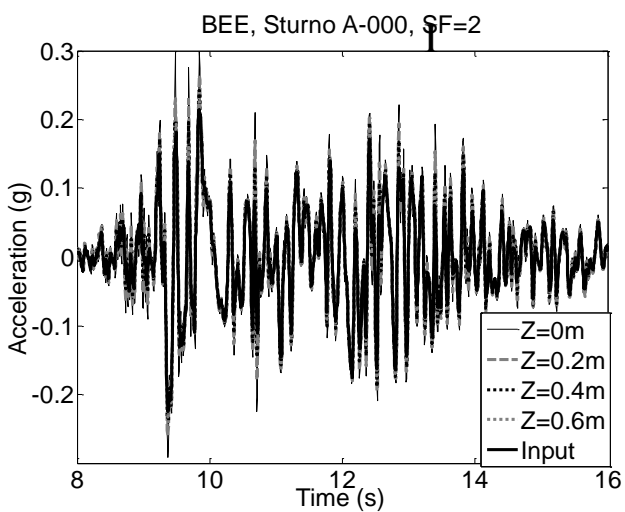

(a)

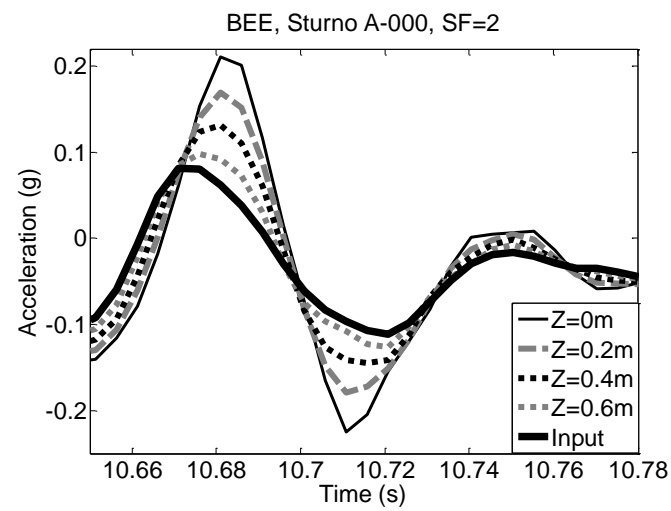

(b)

Fig. 8 Free field acceleration response (a-general, b-detail) for BEE soil configuration, input Sturno-A000, input scale factor $\mathrm{SF}=2$.

Figure 9 shows the outside accelerometer signals and the seismic input being out-of-phase. There is an expected delay of response as we move upwards from Ring 7 to Ring 1. The BEE granular deposit and the stack motions are coupled, as revealed by the free surface and the stack's Ring 1 responses that exhibit a mirror pattern. 


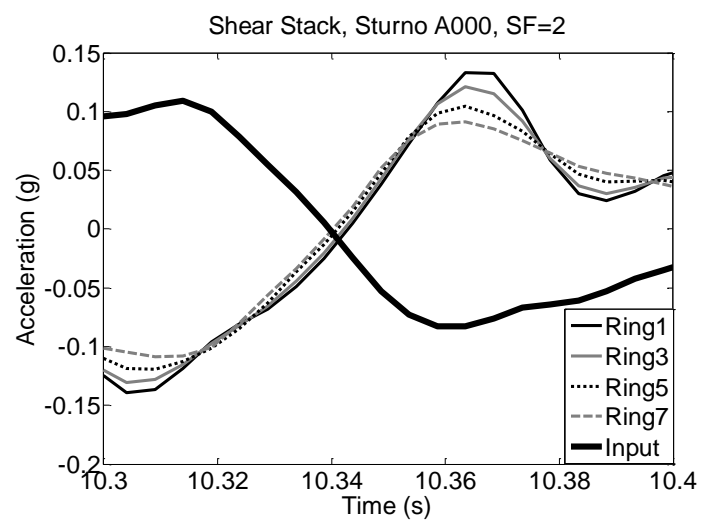

(a)

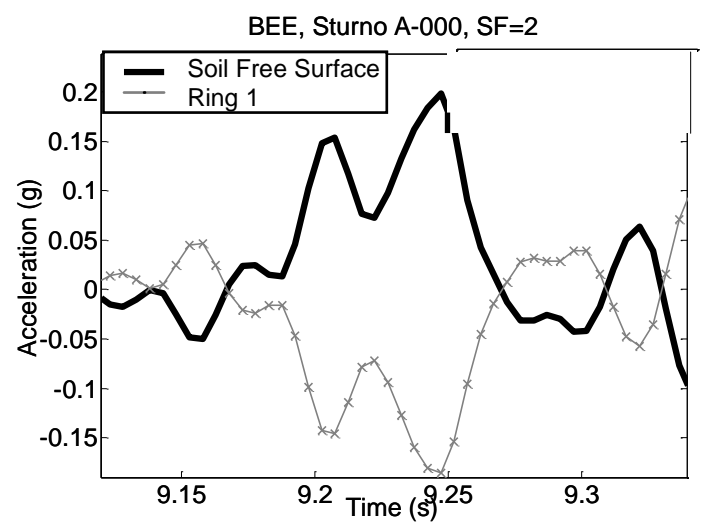

(b)

Fig. 9 Shear stack response (a) and coupling of motions inside and outside the stack (b) for BEE configuration, Sturno-A000, input scale factor $\mathrm{SF}=2$.

In order to investigate more thoroughly the degree of coupling between the shearing granular deposits and the container, frequency response functions (FRFs) were computed between the accelerometer signals and the seismic input at different locations inside and outside the stack. Figure 10 shows the FRFs inside and outside the shear stack for Sturno-A000 input at a frequency scaling factor $S F=2$.
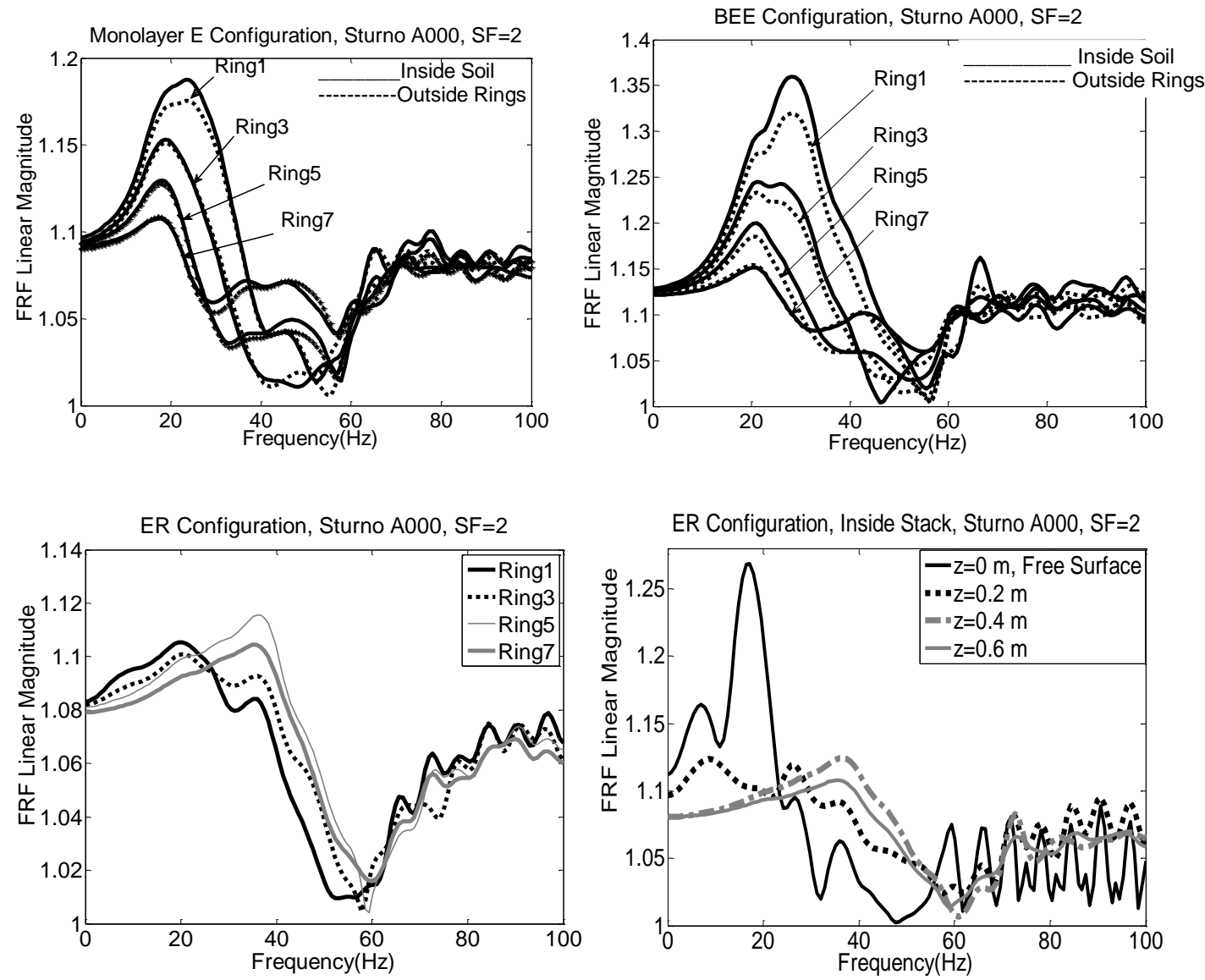

Fig. 10 FRFs outside the shear stack and inside the granular deposits for Sturno-A000 input, input scale factor $\mathrm{SF}=2$.

The monolayer E deposit moves together with the shear stack in fully coupled motion, displaying little differences in motion pattern between the inside and the outside of the shear stack. The twolayer BEE is coupled to the shear stack motion, but the degree of coupling is less pronounced for the top half of the deposit which has lower stiffness (corresponding to Ring 1 and Ring 3 of the 
outside response). As for the ER deposit the top half of the stack (Ring 1 and Ring 3) displays a softer response than the bottom half (Ring 5 and Ring 7) due to the very high stiffness contrast between the inside granular layers $\left(G_{b o t t o m} / G_{t o p}=80\right)$. The transfer functions calculated for the accelerometers located in the top rubber layer $(z=0 \mathrm{~m}$ and $z=0.2 \mathrm{~m})$ do not exhibit any similarities with the transfer functions calculated for the bottom sand layer. This confirms the fact that the shearing pattern in the deposit column is interrupted at the interface between the two layers and that the top half rubber layer becomes decoupled from the shear stack. The free surface of the rubber layer shows an amplified response and its dynamics is characterized by random large displacement vibrations on both vertical and horizontal directions. The rubber layer's low stiffness is insufficient for driving the stack. In this latter case, the response is driven by the container and not by the granular deposit. It is thus confirmed that the relative stiffness between stack and the granular deposit has a paramount influence on the dynamic response and that an accurate investigation of the free field response requires a soft container and a sufficiently stiff deposit.

The normalized peaks of the Frequency Response Functions (FRFs) were instrumental in representing the mode shapes of the granular deposit and of the enclosing container, respectively. The peaks of the FRFs at various ordinates inside and outside the shear stack were normalized against the maximum value of the FRF for the monolayer E configuration. Comparisons between the mode shapes for the monolayer E configuration and the bi-layered BEE, and between the monolayer E and the bi- layered ER are shown in Fig.11a and Fig.11b, respectively. The E and the BEE configurations show a high degree of coupling between deposit and stack, while the ER deposit displays a very different shape from the stack mainly because the low stiffness top rubber layer decouples itself from the stack.

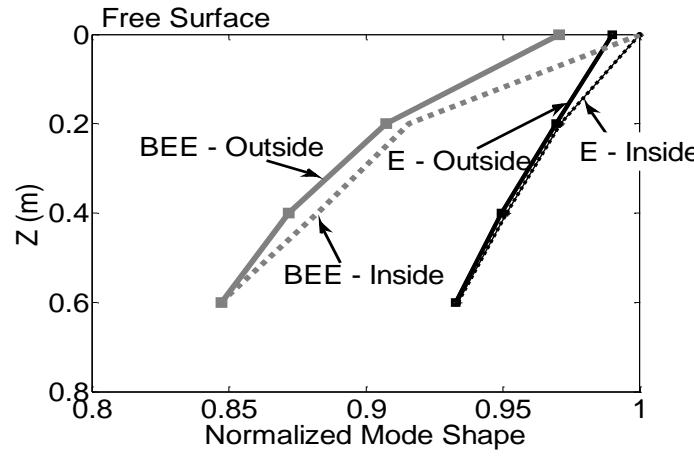

(a)

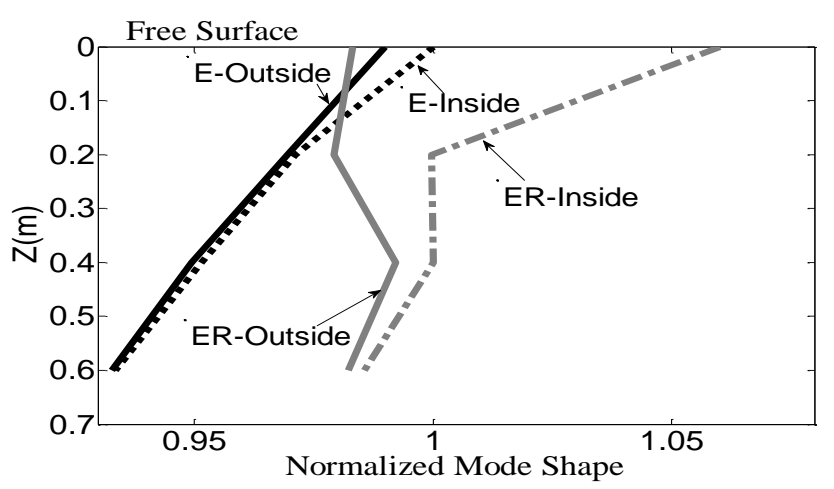

(b)

Fig. 11 Normalized mode shapes for E and BEE deposits (a) and E and ER deposits (b), respectively, inside and outside the shear stack (Sturno-A000 input, input scale factor $\mathrm{SF}=2$ ).

\subsection{Dynamic Stiffness Investigation}

The stress-strain measurements from the seismic tests were employed in a detailed investigation of the small strain stiffness of the deposits. The interpretation of the measured dynamic stiffness was made in relation to the applied dynamic input and to the characteristics of the particulate materials in the deposits. A classic investigation of shear modulus and damping in soils [10] illustrated the importance of the set of factors influencing these two dynamic properties (Table 7). For non-cohesive soils, the relative influence of strain amplitude, effective mean principal stress and void ratio on dynamic stiffness is known to be very high. It is worth observing that particle characteristics have both a direct influence, which is ranked as relatively unimportant, and an indirect influence via the void ratio parameter, whose effect is very strong. One of the objectives of the present study was to determine the influences of dynamic strain magnitude, initial stiffness (void ratio) and input frequency content on dynamic stiffness. 
Table 7 Parameters affecting shear modulus and damping [10]

\begin{tabular}{|c|c|c|c|c|}
\hline \multirow[t]{3}{*}{ Parameter } & \multicolumn{4}{|c|}{ Importance } \\
\hline & \multicolumn{2}{|c|}{ Modulus } & \multicolumn{2}{|c|}{ Damping } \\
\hline & $\begin{array}{l}\text { Clean } \\
\text { Sands }\end{array}$ & $\begin{array}{l}\text { Cohesive } \\
\text { Soils }\end{array}$ & $\begin{array}{l}\text { Clean } \\
\text { Sands }\end{array}$ & $\begin{array}{l}\text { Cohesive } \\
\text { Soils }\end{array}$ \\
\hline Strain Amplitude & $\mathrm{V}$ & $\mathrm{V}$ & $\mathrm{V}$ & $\mathrm{V}$ \\
\hline Effective Mean Principal Stress & $\mathrm{V}$ & $\mathrm{V}$ & $\mathrm{V}$ & $\mathrm{V}$ \\
\hline Void Ratio & $\mathrm{V}$ & $\mathrm{V}$ & $\mathrm{V}$ & $\mathrm{V}$ \\
\hline Number of Cycles of Loading & $\mathrm{R}$ & $\mathrm{R}$ & $\mathrm{V}$ & $\mathrm{V}$ \\
\hline Degree of Saturation & $\mathrm{R}$ & $\mathrm{V}$ & $\mathrm{L}$ & $\mathrm{U}$ \\
\hline Overconsolidation Ratio & $\mathrm{R}$ & $\mathrm{L}$ & $\mathrm{R}$ & $\mathrm{L}$ \\
\hline Effective Strength Envelope & $\mathrm{L}$ & $\mathrm{L}$ & $\mathrm{L}$ & $\mathrm{L}$ \\
\hline Octahedral Shear Stress & $\mathrm{L}$ & $\mathrm{L}$ & $\mathrm{L}$ & $\mathrm{L}$ \\
\hline Frequency of Loading (above $0.1 \mathrm{~Hz}$ ) & $\mathrm{R}$ & $\mathrm{R}$ & $\mathrm{R}$ & $\mathrm{L}$ \\
\hline Other Time Effects (Thixotropy__ & $\mathrm{R}$ & $\mathrm{L}$ & $\mathrm{R}$ & $\mathrm{L}$ \\
\hline $\begin{array}{l}\text { Particle Characteristics (Size, Shape, } \\
\text { Gradation, Mineralogy) }\end{array}$ & $\mathrm{R}$ & $\mathrm{R}$ & $\mathrm{R}$ & $\mathrm{R}$ \\
\hline Soil Structure & $\mathrm{R}$ & $\mathrm{R}$ & $\mathrm{R}$ & $\mathrm{R}$ \\
\hline $\begin{array}{l}\text { Volume Change Due to Shear Strain } \\
\text { (for strains less than } 0.5 \% \text { ) }\end{array}$ & $\mathrm{U}$ & $\mathrm{R}$ & $\mathrm{U}$ & $\mathrm{R}$ \\
\hline
\end{tabular}

* $\mathrm{V}=$ very important, $\mathrm{L}=$ less important, $\mathrm{R}=$ relatively unimportant, $\mathrm{U}=$ relative importance not clearly known

A pseudo-static free-field response of a soil column to a vertically propagating shear wave is conceptually represented in Fig. 12. The lateral deflection vectors $\left(u_{i}(t)\right)$ are instrumental in evaluating the shear stress $\left(\tau_{a-b}(t)\right)$ and the shear strain $\left(\gamma_{a-b}(t)\right)$, when the density $(\rho)$ of the deposit is known (Eqs. 7 and 8).

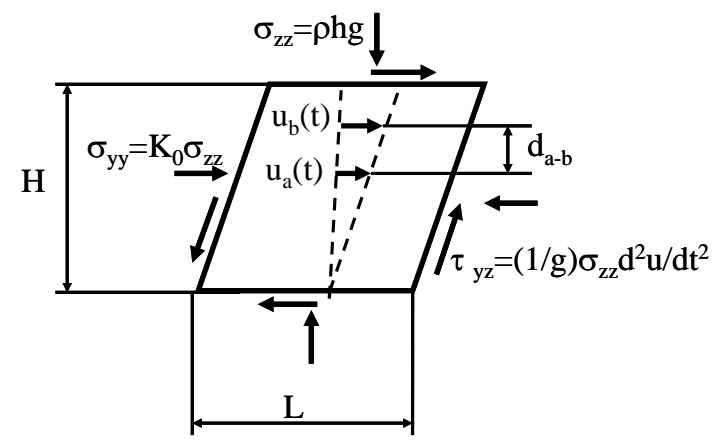

Fig. 12 Idealized soil response to shearing $\left(u_{a}(t)\right.$ and $u_{b}(t)$ displacement vectors at two ordinates inside the deposit)

$\tau_{a-b}(t)=\rho d_{a-b}\left[\ddot{u}_{b}(t)+\ddot{u}_{a}(t)\right] / 2$

$\gamma_{a-b}(t)=\left[u_{b}(t)-u_{a}(t)\right] / d_{a-b}$

In this study, displacement, shear strain and shear stress time histories were evaluated by integrating the measured acceleration time histories. Cumulative trapezoidal integration was combined with filtering for elimination of baseline drifts. A high-pass Butterworth filter of $5^{\text {th }}$ order and a cut-off frequency of $0.5 \mathrm{~Hz}$ were employed to eliminate the low-frequency signal components. The evaluation of strain at the interface between the sandwich layers $(z=0.4 \mathrm{~m})$ for the BEE and the ER deposits, calculated for two different reference ordinates $(\mathrm{z}=0 \mathrm{~m}$ and $\mathrm{z}=0.2$ $m$, respectively) is shown in Fig. 13. It is interesting to see how the width of the shearing layer influences the value of the strain magnitude at the interface, according to Eq.7. It was found that the interface strains calculated against the two selected reference ordinates were of the same order 
of magnitude and displaying a similar pattern for the BEE configuration. However, the interface strains calculated against the two selected reference ordinates were very different for the ER deposit. The ER interface strains calculated against the free surface reference level were unrealistically large, due to the large displacements of the free rubber surface. Therefore, in the ER case, the free surface could not be taken as a reliable reference for computing strain.

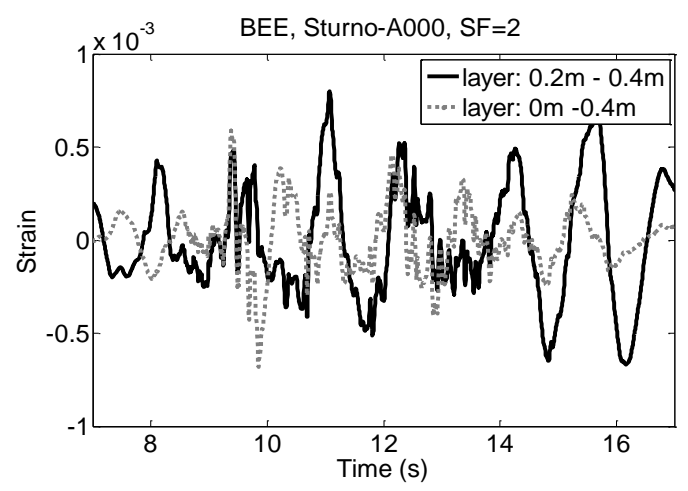

(a)

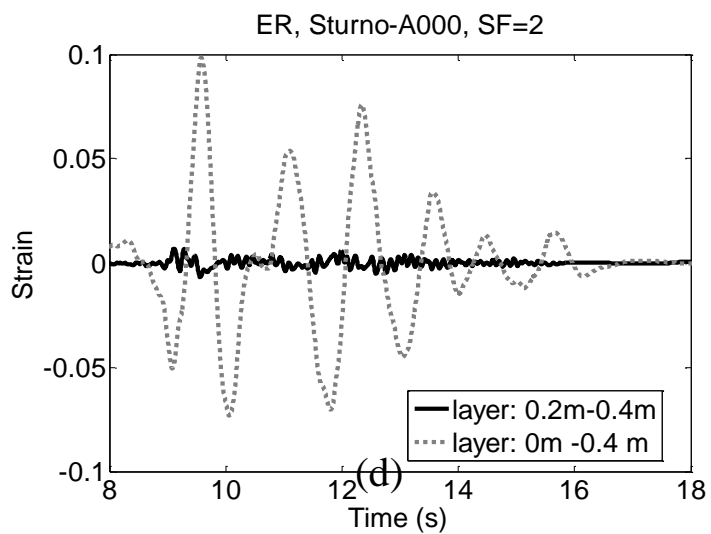

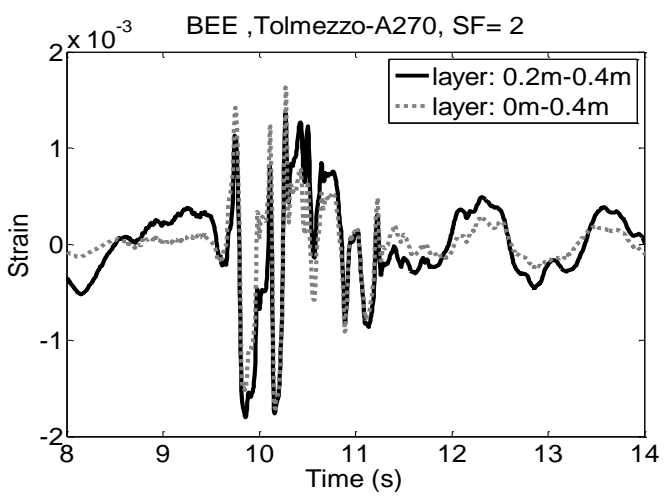

(b)

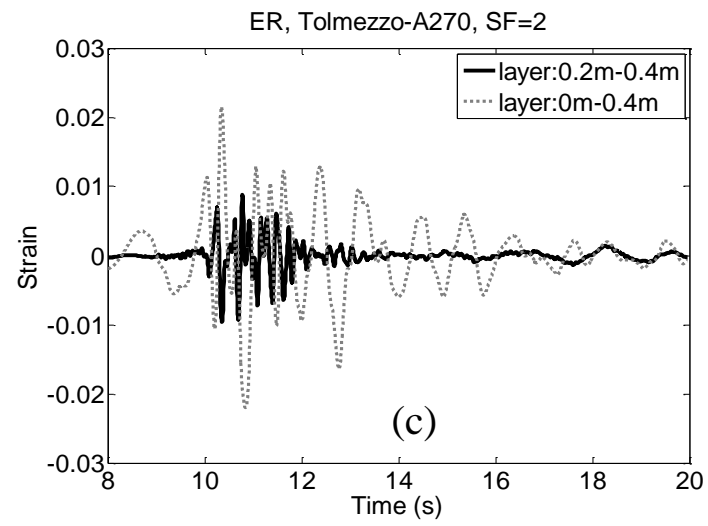

Fig. 13 Strain in soil at interface level $(z=0.4 \mathrm{~m})$ for two deposit configurations (BEE $(\mathrm{a}, \mathrm{b})$, ER (c, d) and two seismic inputs (Sturno-A000 (a, c), Tolmezzo-A270 (b, d), SF=2)

A further analysis of dynamic stiffness was carried out by representing the stress-strain loops for certain cycles extracted from the time histories of the seismic inputs. For example, one of the input cycles extracted from the Tolmezzo-A270, SF=2 acceleration record is shown in Fig. 14. The evaluation of the difference in maximum and minimum shear stress applied during a loop, and the difference in maximum and minimum strain developed in that loop were employed in producing representative dynamic shear moduli. The dynamic strain $(\gamma)$ measurements in the seismic tests ranged up to a maximum value of $0.6 \%$. 


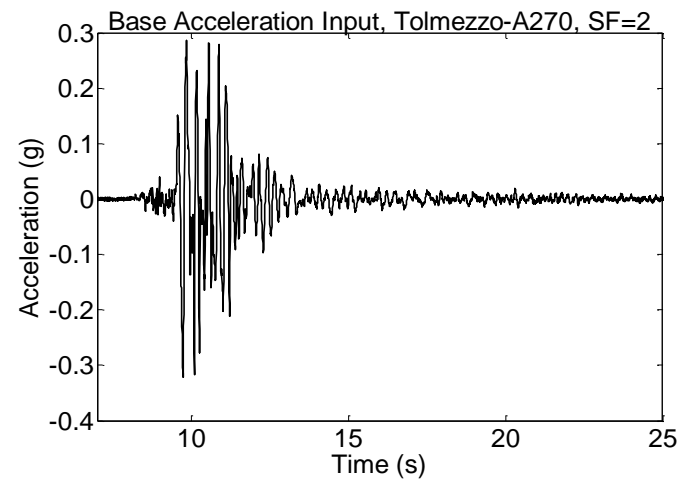

(a)

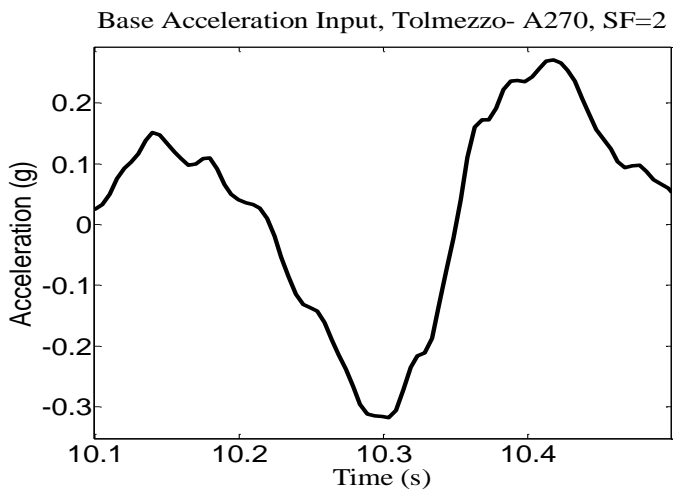

(b)

Fig. 14 Base acceleration input Tolmezzo-A000, SF=2 (a: entire acceleration record, b: cycle extracted for stress-strain investigation)

Figure 15 shows the hysteretic loop for two different input cycles of the time history. The observed hysteretic response for the E monolayer configuration shows a small difference in the shear moduli calculated below and above the interface level $(z=0.4 \mathrm{~m})$.
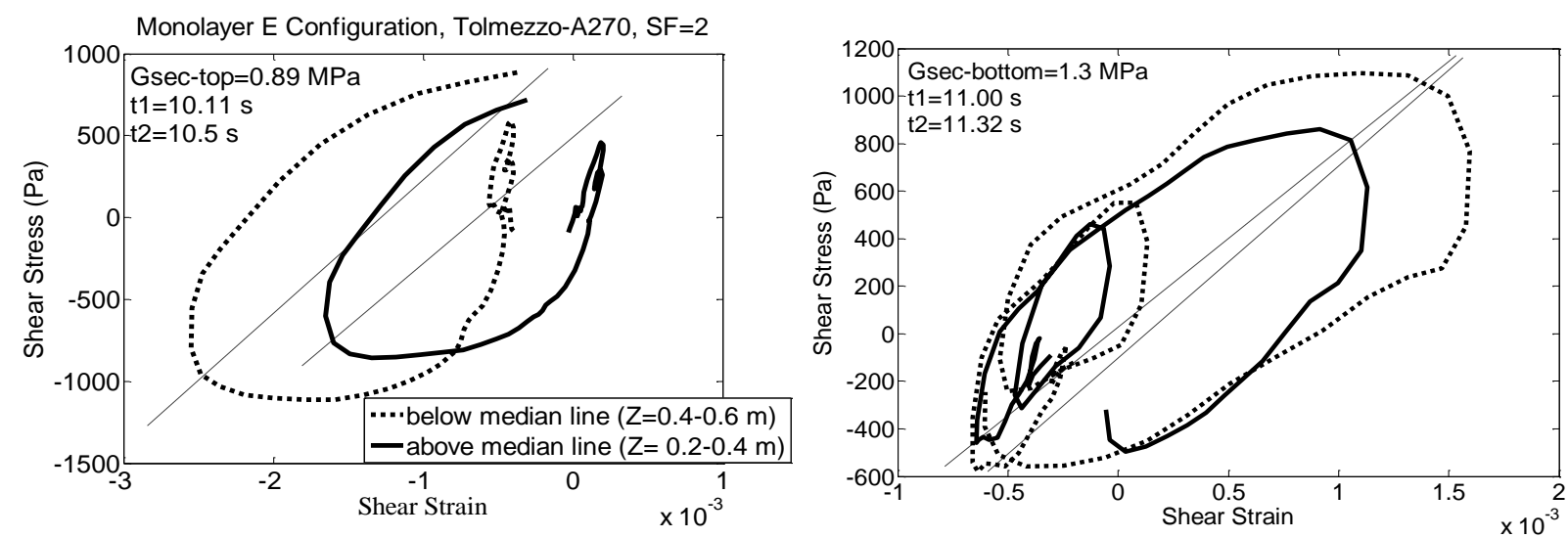

Fig. 15 Observed hysteretic response of soil in the shear stack for monolayer E configuration, input: Tolmezzo-A270, input scaling factor $\mathrm{SF}=2$.

The link between the frequency content of the input and the measured dynamic stiffness moduli was found to be significant. Higher input scaling factors (e.g. $\mathrm{SF}=12$ ) shifted the earthquakes energy to the higher frequency range $(24-48 \mathrm{~Hz}$ ). Higher frequency cycling is associated with higher dynamic stiffness values, which is confirmed in Fig.16. An average stiffness modulus measured for Sturno-A000, $\mathrm{SF}=2$ was about 2.6 $\mathrm{MPa}$, while the modulus measured at $\mathrm{SF}=12$ was in the 4-6 MPa range. Both tests employed the same seismic input (same number of loading cycles $N$ ), but different frequency scaling factors (SF). 


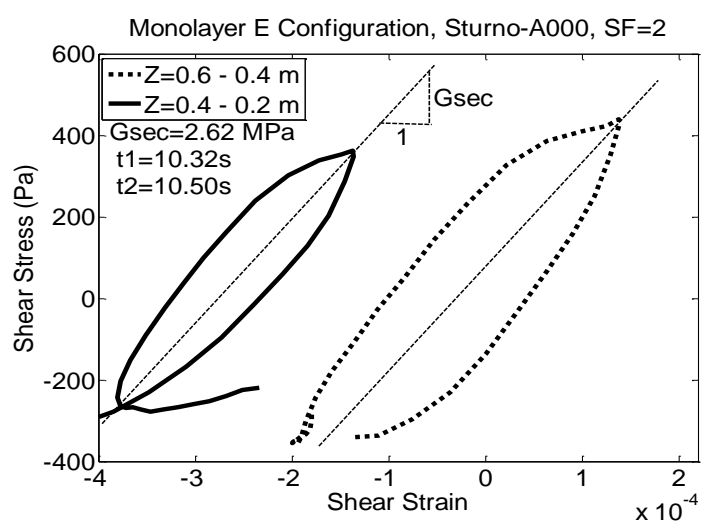

(a)

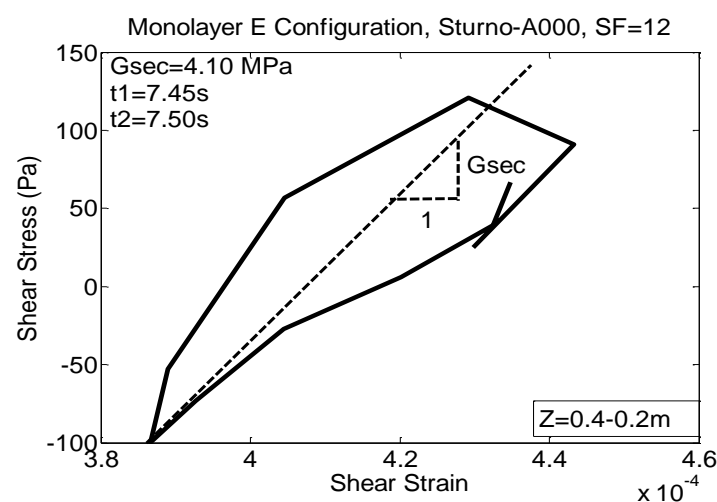

(b)

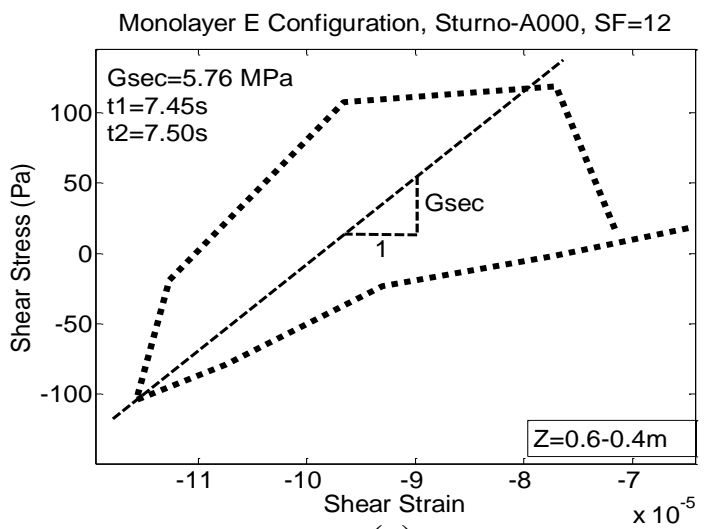

(c)

Fig. 16 Observed hysteretic response of soil in the shear stack for monolayer E configuration, input: Sturno-A000, input scaling factor: $\mathrm{SF}=2$ (a), $\mathrm{SF}=12(\mathrm{~b}, \mathrm{c})$.

The dynamic hysteretic response retains some memory of the initial stiffness of the deposit as it becomes evident for the two layer BEE configuration. Figure 17 shows lower dynamic stiffness for the lower density layer above the median line $(\mathrm{z}=0.4 \mathrm{~m})$.
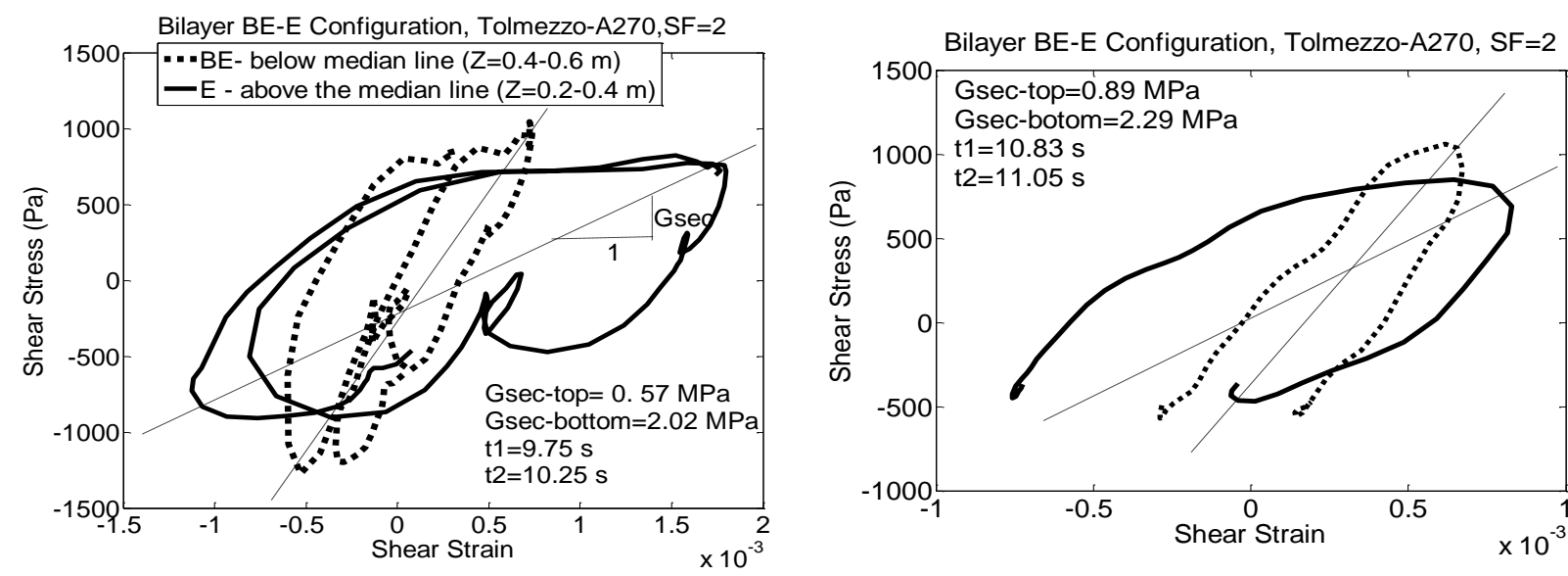

Fig.17 Observed hysteretic response of soil in the shear stack for BEE configuration, input: Sturno-A000, input scaling factor $\mathrm{SF}=2$.

The measured dynamic stiffness values for the deposits under selected seismic conditions were compared to a standard degradation curve for sands [9]. Figure 18 shows that the experimental values for the monolayer E configuration are in reasonable agreement with the the Seed \& Idriss curve. The dynamic moduli measured for the bottom layer in the BEE double layer configuration lie slightly lower under the Seed \& Idriss curve. Overall, the experimental results increase the 
confidence in the dynamic stiffness measurement techniques associated with the shaking table testing.

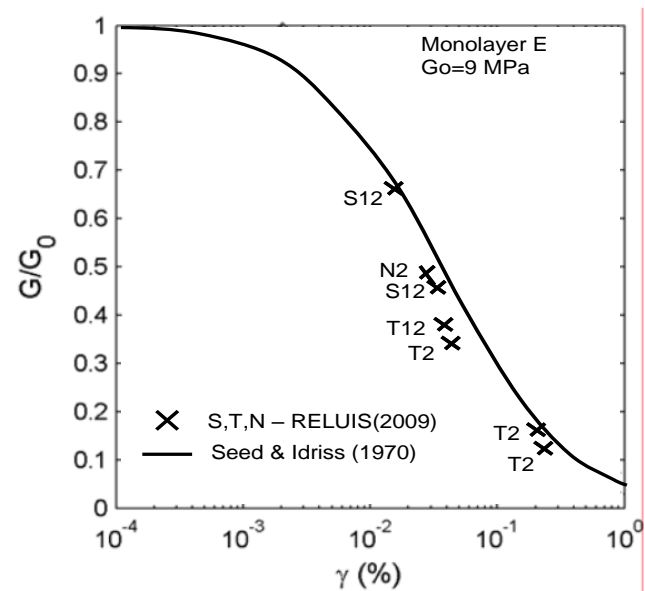

(a)

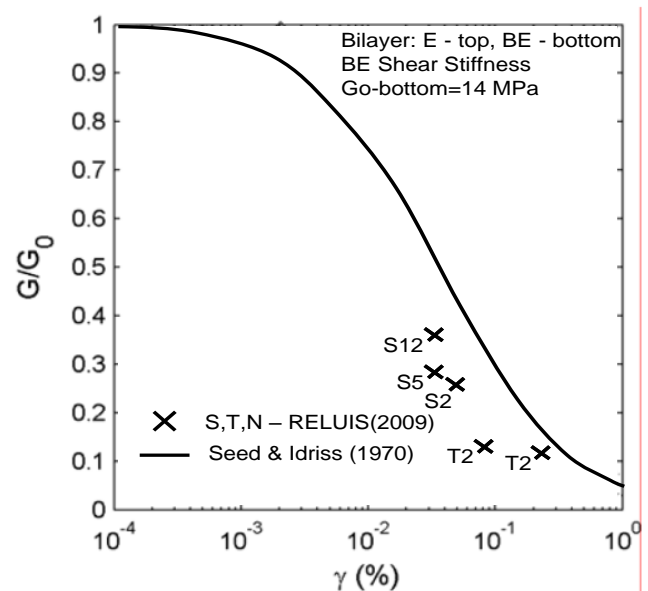

(b)

Fig.18 Dynamic stiffness test results compared with a standard stiffness degradation curve. Monolayer E (a) and bi-layered BEE (b) deposits. Notation: S (Sturno), T (Tolmezzo), $\mathrm{N}$ (Norcia). Ex: S12 = Test Sturno-A000, input scaling factor SF=12.

\section{Concluding remarks}

Shaking table test results of granular materials sheared in plane strain conditions in a large uniaxial shear stack were reported. The shear stress-strain behaviour of three configurations (one witness mono-layered deposit and two bi-layered deposits) was analysed under a set of seismic inputs with different frequency content. Two modal testing techniques (i.e. pulse testing and random white noise testing) were successful in measuring the fundamental periods of the individual layers. The measured fundamental periods of the decoupled granular layers were employed in the calculation of the equivalent fundamental period of the bi- layered deposits by an enhanced Madera procedure ([1]).

The dynamics of the granular deposits was analysed in relation to the inherent stiffness the shear stack, the particulate material characteristics and the dynamic input parameters. The initial stiffness of the test deposits was mainly influenced by the packing density for sands (E and BEE configurations) and by the packing density and particle intrinsic stiffness for the rubber layer. The sand deposits (mono-layered $\mathrm{E}$ and the bi- layered $\mathrm{BEE}$ ) drove the shearing response of the shear stack and exhibited motion coupling inside and outside the shear stack across the vertical direction. The ER configuration that consisted of rubber granules in its top layer was found to exhibit a lower fundamental frequency than the shear stack $\left(f_{E R}=4.25 \mathrm{~Hz}, f_{\text {shear stack }}=6 \mathrm{~Hz}\right)$, therefore its decoupling from the enclosing container during seismic testing was understood. The free surface measurements for the ER configuration were unreliable in strain calculations.

The dynamic hysteretic loops obtained in the experiments show some memory of the initial stiffness of the deposits, as it became evident for the two layered BEE configuration (higher secant stiffness for the dense/stiff bottom layer). The analysis of the hysteretic response of sands and the frequency content of the seismic input shows that higher frequency (24-48 $\mathrm{Hz}$ ) loading cycles resulted in higher values of measured dynamic stiffness in both the monolayer and the stratified deposits. The shear stress-shear strain results for the mono-layered and the bi-layered sand deposits compare well with previous commonly-used empirical curves for sands [9], increasing the 
confidence in the shaking table and shear stack testing for the dynamic investigation of granular media.

\section{Acknowledgements}

The financial support from ReLUIS (Rete di Laboratori Universitari Ingegneria Seismica) for conducting this research is gratefully acknowledged. The authors would like to thank Eleonora Iannacce and Domenico Lombardi for their contribution to the experimental work and to Professor David Muir Wood for his advice on granular material testing.

\section{References}

[1] Hadjian, A.H. Fundamental period and mode shape of layered soil profiles. Soil Dyn Earthquake Eng 2002; 22: 885-91.

[2] Gazetas G. Soil dynamics: an overview. In: Banerjee P.K. \& Butterfield R., editors. Dynamic behaviour of foundations and buried structures. Elsevier Science Publishing Co., 1987

[3] Novak M. Experimental studies of the dynamic behaviour of piles and pile groups. In: Banerjee P.K. \& Butterfield R., editors. Dynamic behaviour of foundations and buried structures. Elsevier Science Publishing Co., 1987.

[4] Badoni D., Makris N. Nonlinear response of single piles under lateral inertial and seismic loads. Soil Dyn Earthquake Eng 1996; 15: 29-43.

[5] Tokimatsu K., Mizuno H., Kakurai M. Building damage associated with geotechnical problems. Special issue Soils and Foundations, Japanese Geotechnical Society, 1996; Jan: 219-34.

[6] Mylonakis G., Nikolaou A., Gazetas G. Soil-pile-bridge seismic interaction: kinematic and inertial effects. Earthquake Eng Struct Dyn 1997; 26:337-59.

[7] Bhattacharya S.A Review of methods for pile design in seismically liquefiable soils. In: Bhattacharya S., editor. Design of foundations in seismic areas: principles and applications. National Information Centre of Earthquake Engineering. Indian Institute of Technology, Kanpur,ISBN 81-904190-1-3, 2007.

[8] Richart, F.E, Jr., Hall, J.R., Jr., Woods, R.D. Vibrations of soils and foundations. Prentice-Hall, Englewood Cliffs, N.J.;1970.

[9] Seed, H.B., Idriss, I.M. Soil moduli and damping factors for dynamic response analysis. Rep. No. EERC 70-10. Earthquake Engineering Research Centre, Berkeley, CA.; 1970.

[10] Hardin, B.O., Drnevich, V.P. Shear modulus and damping in soils. J. Soils Mech. Found. Div. 1972a; 98(7):667-92.

[11] Vucetic, M., Dobry, R. Effect of soil plasticity on cyclic response. J. Geotech. Eng. 1991; 117(1):89-107.

[12] Ishibashi, I., Zhang, X.J. Unified dynamic shear moduli and damping ratios of sand and clay. Soils Found. 1993; 33(1):182-91.

[13] Darendelli, M.B. Development of a new family of normalized modulus reduction and material damping curves. PhD thesis. Univ. of Texas at Austin, Austin, TX; 2001. 
[14] Ohtsuki A., Hirota M., Ishimura K., Yokoyama K., Fukutake K. Verification of twodimensional non-linear analysis of sand-structure system by examining the results of the shakingtable test. Earthquake Eng \& Structural Dynamics, 1992, 21(7); 591-607.

[15] Meymand P.J. Shaking table scale model tests of nonlinear soil-pile-superstructure interaction in soft clay. Ph.D.thesis. Berkeley, CA: The University of California, Berkeley, 1998.

[16] Prasad S.K., Towhata I., Chandradhara G.P., Nanjunaswamy P. Shaking table tests in earthquake geotechnical engineering. Curr Sci 2004; 87 (10):1398-404.

[17] Tokimatsu K., Susuki, H. Effect of inertial and kinematic interactions on seismic behaviour of pile foundations based on large shaking table tests. Proc. $2^{\text {nd }}$ CUEE Conf. Urban Earthquake Eng, Tokio Institute of Technology, 2005.

[18] Pitilakis D., Dietz M, Muir Wood D., Clouteau D., Modaressi A. Numerical simulation of dynamic soil-structure interaction in shaking table testing. Soil Dyn Earthquake Eng 2008; 28: 453-67.

[19] Takahashi A., Takemura J., Susuki A., Kusakabe O. Development and performance of an active type shear box in a centrifuge. Int. J. Phys. Model Geotech 2001; 1(2):1-18.

[20] Dar A.R. Development of a flexible shear stack for shaking table testing of geotechnical problems. PhD Thesis, University of Bristol, 1993.

[21] Fishman K.L., Mander J.B. \& Richards R. Laboratory study of seismic free-field response of sand. Soil Dyn Earthquake Eng 1995; 14: 33-43.

[22] Gibson A.D. Physical scale modelling of geotechnical structures at one-g. Ph.D.thesis. Pasadena, CA: California Institute of Technology; 1997.

[23] Turan A., Hinchberger S., Naggar H.E. Design and commissioning of a laminar soil container for use on small shaking tables. Soil Dyn Earthquake Eng 2009; 29: 404-14.

[24] Ashford, S. and Jakrapiyam, W. Design and verification of the UCSD laminar container. SSRP 2001-07, University of California, San Diego; 2001.

[25] Thevanayagam, S. et al. Laminar Box System for 1-g Physical Modeling of Liquefaction and Lateral Spreading", Geotechnical Testing Journal 2009; 32(5).

[26] Chang, B.J., and Hutchinson, T.C..Experimetnal evaluation of p-y curves considering liquefaction development. SSRP-09/13, University of California, San Diego; 2010.

[27] Crewe A.J., Lings M.L., Taylor C.A., Yeung A.K., Andrighetto R. Development of a large flexible shear stack for testing dry sand and simple direct foundations on the shaking table. In: Elnashai, editor. European seismic design practice. Rotterdam: Balkema; 1995.

[28] German R. Particle Packing Characteristics, Metal Powder Industries Federation, New Jersey; 1989.

[29] Roberts M. J. Signals and systems: analysis using transform methods and MATLAB. McGraw-Hill Professional. ISBN 0072499427; 2004 
[30] Blackledge J.M. Digital signal processing: mathematical and computational methods, software development and applications. Horwood Publishing. ISBN 1898563489; 2003

[31] Dihoru, L., Bhattacharya, S., Taylor, C.A., Muir Wood, D., Moccia, F., Simonelli, A.L. \& Mylonakis, G.. Experimental modelling of kinematic bending moments of piles in layered soils. In (Eds) Kokusho, Tsukamoto \& Yoshimine, Proc. Performance-based design in earthquake geotechnical engineering, Tokio, Japan, 2009.

[32] Moccia F. Seismic soil pile interaction: experimental evidence. PhD.thesis. Naples, IT: Università degli studi di Napoli 'Federico II', 2010.

[33] Madera, G.A. Fundamental period and amplification of peak acceleration in layered systems. Research Report R 70-37, June. Cambridge, MA: MIT Press; 1970. 